\title{
The piggybacking stingray
}
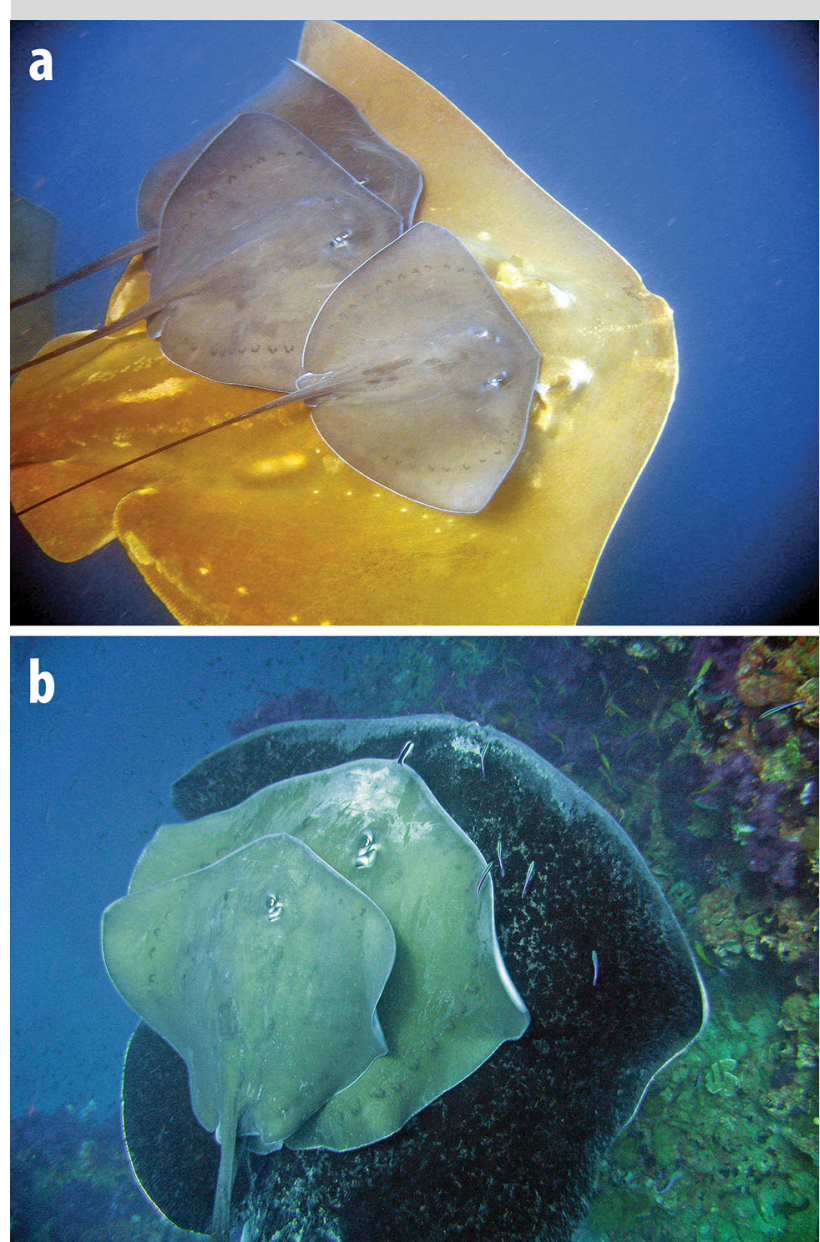

The pink whipray, Himantura fai, is a large (maximum disc width $146 \mathrm{~cm}$ ) ray that occurs in coastal soft-sediment habitats in the Indian Ocean, northern Australia and parts of Southeast Asia to Micronesia in the western Pacific (Last and Stevens 2009). Behaviourally, the species is unique because multiple individuals often piggyback on members of the same species (Last and Stevens 2009) and on other, larger stingrays. The photographs shown in Fig. 1 were taken in 2015 in water 20-30 m deep at the wreck of the Yongala off Townsville on the Great Barrier Reef $\left(19^{\circ} 18.274^{\prime}\right.$ S, $147^{\circ} 37.341^{\prime} \mathrm{E}$ ) and show pink whiprays piggybacking on a smalleye stingray (Dasyatis microps, distributed in the Indo-West Pacific from Mozambique to Arafura Sea; Fig. 1a is a new record of the occurrence of this species in Australian coastal waters) and on the blotched fantail ray (Taeniurops meyeni; Fig. 1b). The reasons for this behaviour are unknown, although it has been observed for this species in other locations such as Indonesia and the Maldives (W. White pers. obs.). One possibility is that piggybacking is a predator defence strategy that allows the smaller rays to appear larger than they actually are and breaks up silhouettes on which predators can focus. There may also be some hydrodynamic or foraging advantage to the smaller rays in travelling with larger species in this manner, although this does not explain why these rays piggyback on other rays resting on the seabed (see Electronic Supplementary Material, ESM, Fig. S1) or at cleaning stations. Reports of interspecific behavioural interactions among elasmobranchs, other than in the context of predation, are relatively rare. A better understanding of the piggybacking behaviour and associated advantages it provides to the pink whiprays (and possibly also the host species) may help to identify key evolutionary drivers of stingray behaviour and ecology.

\section{Reference}

Last PR, Stevens JD (2009) Sharks and rays of Australia. CSIRO Publishing, Melbourne

Electronic supplementary material The online version of this article (doi:10.1007/s00338-016-1429-9) contains supplementary material, which is available to authorized users.

Fig. 1 a Pink whipray, Himantura fai, piggybacking on a smalleye stingray (Dasyatis microps) swimming near the seabed. In other photographs of this event (ESM Fig. S1), a group of 6-11 pink whiprays can be seen accompanying the smalleye stingray. b Pink whiprays piggybacking on a blotched fantail ray (Taeniurops meyeni) at a cleaning station. Note the cleaner wrasses Labroides dimidiatus on the dorsal surface of the rays

\section{G. Meekan $(\bowtie)$}

Australian Institute of Marine Science, Perth, WA, Australia

e-mail: m.meekan@aims.gov.au

L. Trevitt

Yongala Dive, 56 Narrah St, Alva, QLD 4807, Australia

C. A. Simpfendorfer

College of Marine and Environmental Sciences, James Cook University, Townsville, QLD, Australia

\section{W. White}

CSIRO Australian National Fish Collection, Hobart, TAS 7000, Australia

Received: 16 December 2015/ Accepted: 25 February 2016/Published online: 11 March 2016

(C) Springer-Verlag Berlin Heidelberg 2016 